(RESEARCH ARTICLE)

\title{
Heat-induced changes of corn, potato, and wheat starches
}

\author{
Popova Aneta Tincheva * \\ Department of Catering and tourism, University of food technologies, 26 Maritsa blvd., 4000, Plovdiv, Bulgaria.
}

Publication history: Received on 10 November 2019; revised on 17 November 2019; accepted on 21 November 2019

Article DOI: https://doi.org/10.30574/wjarr.2019.4.1.0087

\begin{abstract}
Light microscopy was used to study the native and heat-induced changes of corn, potato, and wheat starch suspensions. The starch dispersions were subjected to water bath treatment at $70^{\circ} \mathrm{C}$ for $12 \mathrm{~min}, 80^{\circ} \mathrm{C}$ for $12 \mathrm{~min}, 90^{\circ} \mathrm{C}$ for $12 \mathrm{~min}$, and $100{ }^{\circ} \mathrm{C}$ for 6 minutes. Significant structural changes were observed between $90{ }^{\circ} \mathrm{C}$ and $100{ }^{\circ} \mathrm{C}$, and potato starch was identified as the most resistant to heat-induced changes. The granule structure broke down resulting in amylose dispersion.
\end{abstract}

Keywords: Amylose; Amylopectin; Heating; Gelatinization; Starch; Swelling

\section{Introduction}

Starch is a polysaccharide accumulated as an energy reserve in seeds, roots, and fruits in the form of starch grains. It consists of amylose and amylopectin (fig. 1). Proteins, lipids, moisture, and ash (minerals and salts) are also present in starch granules in very small quantities [1]. The amylose/amylopectin ratio differs between starches, but typical amylose and amylopectin levels are between 25-75\%. Amylose content in wheat starch is between 23\% and 35\% [2]; in potato starch $27 \%$ [3], and in corn starch between 24.74 to $30.32 \mathrm{~g} / 100 \mathrm{~g}$ [4]. Amylose is a linear polymer composed almost entirely of $\alpha$-1,4-linked D-glucopyranose [5], while amylopectin is composed of $\alpha$-1,4-linked glucose segments connected by $\alpha-1,6$-linked branch points. Starch is considered a cheap and available material with application in the food, pharmaceutical and other industries because of its lack of taste and odor. In the gastrointestinal tract of humans and animals, the starch dissolves, undergoing hydrolysis under the influence of the amylase enzyme, and becomes glucose, which is absorbed by the body.

Starch comprises a large percentage of the daily calories consumed by people, since grains contain generally $60-75 \%$ starch [6]. Starches maintain good nutritional management when dealing with diabetes and obesity. Authors classify starches as slowly digested, rapidly digested and non-digested. Slowly digested and non-digested starches are linked to energy control intake, while rapidly digested - to overconsumption. Starches that are relatively high in amylose content tend to be more resistant to digestion than starches with higher amylopectin content [7]. A starch rich diet is associated with lower body weight, and fat mass [8].

\footnotetext{
${ }^{*}$ Corresponding author

E-mail address: popova_aneta@yahoo.com
} 
<smiles>CO[C@H]1O[C@H](CO)[C@@H](O[C@@H]2OC(CO)[C@H](O[C@H]3OC(CO)[C@H](OC)[C@H](O)C3O)[C@H](O)[C@H]2O)[C@H](O)[C@H]1O</smiles>

Amylose

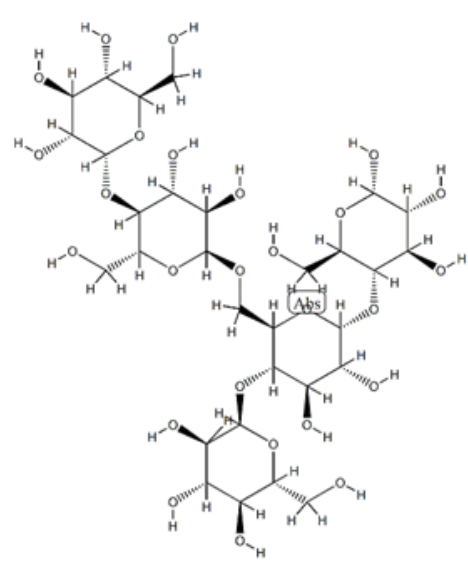

amylopectin

Figure 1 Structure of amylose and amylopectin

Starches are common ingredients to instant soups, bakery goods, confectionary products [9]. Native starches possess a granular structure. The particle size depends on starch type, and potato starch is considered the one with the largest size granules. The size and shape of the starch granules is determined by the branched structure of amylopectin rather than amylose [10]. The granule size appeared to correlate with gelatinization temperature. The smaller the size of starch granule, the higher the gelatinization temperature [10]. The physical and chemical characteristics of the granule starches are involved in their properties and functionality. Smaller starch granules have a larger superficial area, surface pores, and channels that enhance water uptake. High hydration increases the swelling, viscosity, and gelatinization ability of starch granules [11].

Potato starch derives from the tubers of the Solanaceae family. Potato starch is reported to have a low gelatinization temperature, high swelling ability and solubility, and low tendency to retrograde [12]. Potato starch find its application in both food and other industries especially as a thickener. Corn starch, also known as maize starch, is derived from the fruits of the Gramineae family. Corn starch is an important ingredient in products which need gelling, water retention or thickening [13]. Wheat starch is obtained from the fruits of Triticum species. Starches from soft wheat contain high amounts of surface lipids and proteins and exhibit lower paste viscosity, whereas that from hard cultivars contain high proportion of small granules and amylose content but lower gelatinization temperature and enthalpy [14]. Isolated wheat starch is often utilized in gluten-free products, but starch-based ingredients should ideally originate from raw materials that are naturally gluten-free [15].

The aim of this research was to evaluate the heat-induced changes of three widely used starches: potato, corn, and wheat and to compare their physicochemical and structural properties.

\section{Material and methods}

Corn, potato and wheat starches (produced and distributed by "Bioset" LTD) were purchased from a local supermarket in Plovdiv, Bulgaria in September 2019.

\subsection{Dispersion preparation}

Two percent starch dispersions were prepared with distilled water. After that, they were heated in a water bath in a range of $65-100{ }^{\circ} \mathrm{C}$. The starch dispersions were subjected to water bath treatment at $70{ }^{\circ} \mathrm{C}$ for $12 \mathrm{~min}, 80 \stackrel{\circ}{ } \mathrm{C}$ for 12 $\min , 90^{\circ} \mathrm{C}$ for $12 \mathrm{~min}$, and $100^{\circ} \mathrm{C}$ for 6 minutes.

\subsection{Light microscopy of starch dispersions}

The microstructure of the starch dispersions was assessed by light microscopic assay using a method adapted from Langton and Hermansson [16]. The samples were examined with a Celestron LCD Digital II microscope. Micrographs were made by means of an 8MP digital camera. 


\section{Results and discussion}

The description of starch contributes to the basic knowledge of starches used in food industry. Native wheat starch (fig. 1-C) has to oval shaped granules, and only few of them are pointed. The typical size of the granule varies from $2 \mu$ to 8 $\mu$. The maize starch grains (fig. 1-B) can exhibit differences in their shape depending on the part of grains they are derived from. Those from the center of the grain are irregularly round, while others from the mealy center of the endosperm are pear shaped or elongated. Potato starch grains (fig. 1-A) are the biggest compared to those of maize and wheat starch. Their shape is ellipsoidal and some are oval.
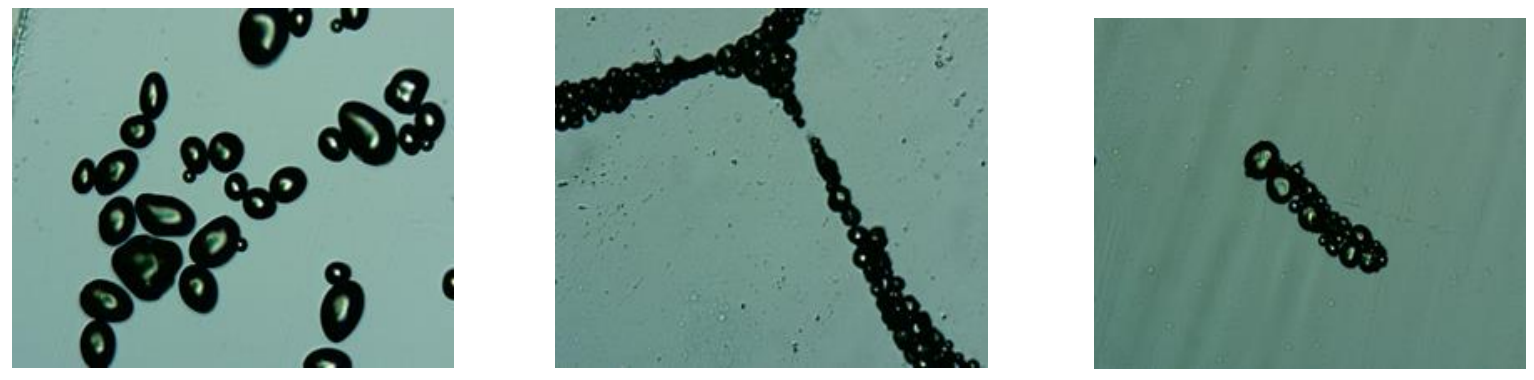

Figure 2 Native starches: A - potato; B - corn; C - wheat

Starch grains are insoluble in cold water due to their hydrogen bonds and the crystallinity of the molecule. When starch is dispersed in hot water, the starch granules swell and enlarge several times in size, destroying their molecules and extracting amylose, respectively, to form a three-dimensional structure and increase the viscosity of the gel. When the starch molecules are heated in water, the semi-crystalline structure is disturbed and the water molecules bind via hydrogen bond to hydroxyl groups exposed to the amylose and amylopectin molecules [17].

When the starch suspension is warmed up to $55^{\circ} \mathrm{C}$, its structure begins to change; it absorbs water and slightly swells. This swelling is reversible. Heating in the range of 50-65 ${ }^{\circ} \mathrm{C}$ is the first stage of gelatinization - swollen starch grains with disturbed internal structure. This stage of swelling of starch grains is the initial step of all other characteristics of the gel. Starch grains increase their volume by up to $30 \%$. The ingestion of water and the heating of the starch dispersion destroys the hydrogen bonds responsible for the cohesion of the grains, partially dissolving the starch. Water penetrates the inside of the starch grain, hydrating the linear fragments of amylopectin. This process results in irreversible swelling, increasing the grain size several times as well as the viscosity of the starch paste. At $80{ }^{\circ} \mathrm{C}$, the swelling is irreversible [18].

The swelling capacity and starch solubility illustrates the interactions of polymer chains containing amorphous and crystalline grain fractions. The extent of this interaction is influenced by the amylose-amylopectin ratio and is characteristic of each molecule depending on the degree of polymerization, the length and degree of branching of the chain, the molecular weight and molecular conformation $[19,20]$.

When starch grains swell and its components are in solution, the properties of the medium change from a simple suspension of starch granules to starch paste. Amylose and amylopectin form separate phases due to thermodynamic immiscibility. Starch paste may contain unaltered grains, partially swollen, aggregates of swollen starch grains, fragments and molecules of retrograde starch and starch that has dissolved or precipitated [21, 22]. The presence of relatively short chains of amylose and amylopectin is characterized by the opacity of the starch suspensions and the foods containing them. The suspensions usually exhibit a viscosity peak that begins after swelling and increases in the process of starch grain starch, followed by a decrease in viscosity due to grain degradation and polymer stacking [23, 24].

Microscopic techniques portray very well the shape and size of starch granules. Microstructural changes have been studied as a function of temperature treatment. The starches differed widely in the extent of amylose leaching, degree of swelling, gelatinization transition temperatures. The effect of heating of potato (fig. 3), corn (fig. 4), and wheat (fig. 5) starches is illustrated at $70{ }^{\circ} \mathrm{C}$ for $12 \mathrm{~min} ; 80^{\circ} \mathrm{C}$ for $12 \mathrm{~min} ; 90^{\circ} \mathrm{C}$ for $12 \mathrm{~min}$; and $100^{\circ} \mathrm{C}$ for 6 min. Changes occurred at each stage of the heating with significant differences between the studied varieties of starches.

There is a variation of the degree of swelling in all of the samples, and it is important to state that potato starch appeared to be the most resistant to heating confirming the relation grain size - gelatinization temperature by Abdullah et al. [10]. 
At $70 \stackrel{\circ}{ } \mathrm{C}$, the granules of the potato starch are at the first stage of swelling according to the patterns described by AlcarazAlay et al. [25]. They have increased in volume but still no leakages are observed. At $80{ }^{\circ} \mathrm{C}$, gelatinization has occurred and it can be seen that few granules have leaked out. At 90 and $100 \stackrel{\circ}{\circ}$, the potato starch has formed a glue like white paste and breaking of granules characterizes the smears. A similar trend was noticed in the studies conducted by Reddy et al. [26].

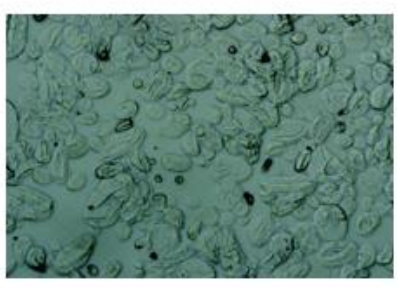

A

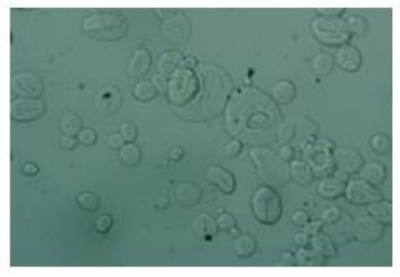

C

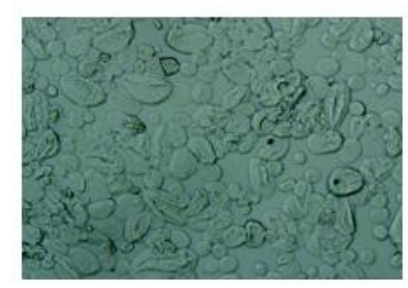

B

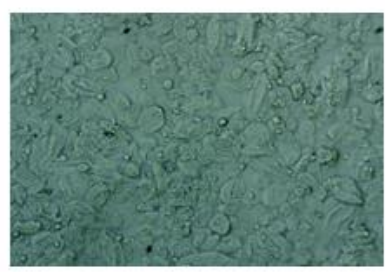

D

Figure 3 Heat-induced changes in potato starch: A - $70^{\circ} \mathrm{C}, 12 \mathrm{~min}$; $\mathrm{B}-80^{\circ} \mathrm{C}, 12 \mathrm{~min} ; \mathrm{C}-90^{\circ} \mathrm{C}, 12 \mathrm{~min}$; $\mathrm{D}-100{ }^{\circ} \mathrm{C}, 6$ min.

When characterizing corn starch, it can be concluded that gelatinization occurs before $70{ }^{\circ} \mathrm{C}$ because leakages are observed at fig. 4-A. There are several granules with amylose that has leaked out at $80{ }^{\circ} \mathrm{C}$. From some smears, it is not possible to characterize the exact shape of the starch granules (fig. 4-C and 4-D). The results established in the current study are comparable to the changes described by Ratnayake and Jackson [27] and further discussed by Wang et al. [28].

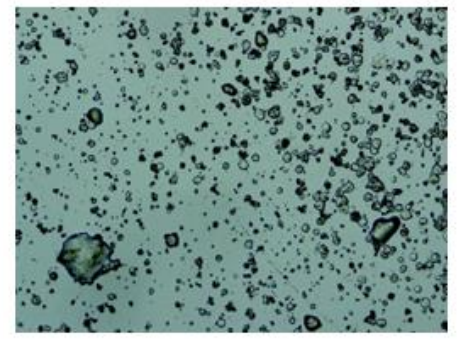

A

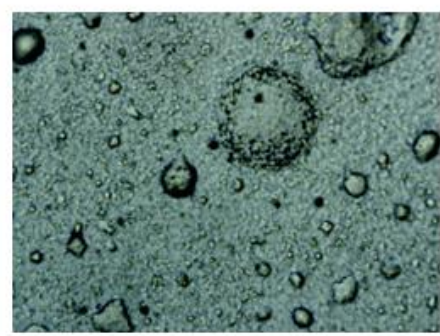

C

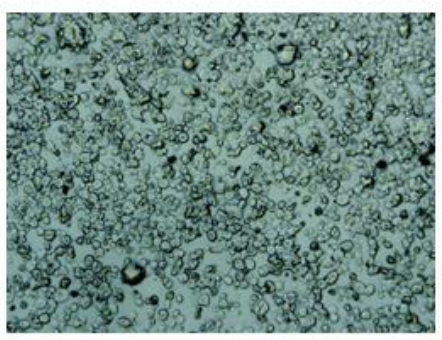

B

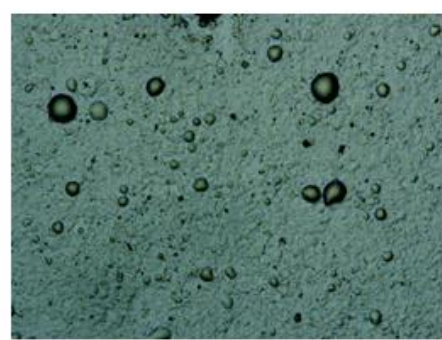

D

Figure 4 Heat-induced changes in corn starch: A $-70{ }^{\circ} \mathrm{C}, 12 \mathrm{~min}$; $\mathrm{B}-80{ }^{\circ} \mathrm{C}, 12 \mathrm{~min} ; \mathrm{C}-90{ }^{\circ} \mathrm{C}, 12 \mathrm{~min} ; \mathrm{D}-100{ }^{\circ} \mathrm{C}, 6$ $\min$ 
The granules of the wheat starch are at the first stage of swelling at $70{ }^{\circ} \mathrm{C}$ according to the patterns described by Noisuwan et al. [29]. A number of granules in the second stage of swelling can also be seen in Fig. 5-A and 5-B. The presence of an amylose-rich phase in the center of the granules is observed in fig. 5-C and it appeared quite difficult to characterize the exact shape of the starch granules in fig. 5-D because the breaking of granules and amylose release dominated in the smears. Swelling of starch granules increased progressively with temperature increasing. Chen et al. [30] have also documented that when being heated, wheat granules undergo significant structural changes prior to the visible morphological changes taking place during gelatinization.

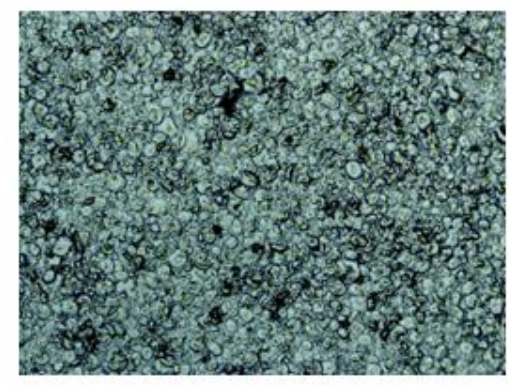

A

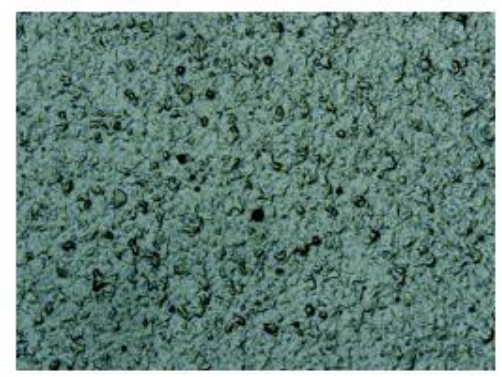

C

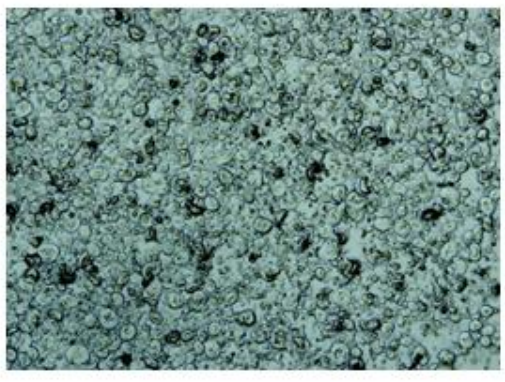

B

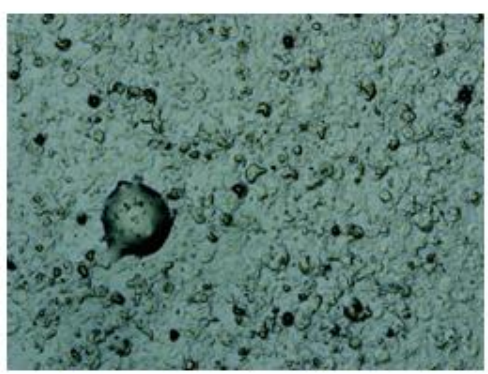

D

Figure 5 Heat-induced changes in wheat starch: $\mathrm{A}-70^{\circ} \mathrm{C}, 12 \mathrm{~min} ; \mathrm{B}-80^{\circ} \mathrm{C}, 12 \mathrm{~min} ; \mathrm{C}-90^{\circ} \mathrm{C}, 12 \mathrm{~min} ; \mathrm{D}-100{ }^{\circ} \mathrm{C}, 6$ $\min$

\section{Conclusion}

The currently established results point out that the physicochemical differences in the corn, potato, and wheat starch gels are mainly due to the extent of starch granules damage caused by different treatments. The initial gelatinization temperatures for different varieties of starches were in the range of 55-70 ${ }^{\circ} \mathrm{C}$. Heat treatments affect starch properties, such as the granule morphology, crystallinity, swelling, gelatinization and retrogradation. Further research can clear out paths for starch modifications without the use of enzymes or other chemical products and possible ways to develop food products with functional properties.

\section{Compliance with ethical standards}

\section{Disclosure of conflict of interest}

Author declare no conflict of interest exist.

\section{References}

[1] Sjöö M and Nilsson L. (2017). Starch in food: Structure, function and applications, Second edition. Woodhead Publishing, USA, 305-416.

[2] Majzoobi M, Farahnaky A and Amiri S. (2011.) Physicochemical characteristics of starch component of wheat flours obtained from fourteen Iranian wheat cultivars. International Journal of Food Properties, 14(4), 685-696. 
[3] Stawski D. (2008). New determination method of amylose content in potato starch. Food Chemistry, 110(3), 777 781.

[4] Ahmad Mir S, Bosco S, Bashir M, Ahmad Shah M and Maqbool Mir M. (2017). Physicochemical and structural properties of starches isolated from corn cultivars grown in Indian temperate climate. International Journal of Food Properties, 20(4), 821-832.

[5] Zobel HF. (1988). Molecules to granules: A comprehensive starch review. Starch/Staerke, 40, 44-50.

[6] Gaesser GA. (2007). Carbohydrate quantity and quality in relation to bodymass index. Journal of the American Dietetic Association, 107, 1768-80.

[7] Aller E, Abete I, Astrup A, Martinez JA and Van Baak MA. (2011). Starches, sugars and obesity. Nutrients, 3(3), 341-369.

[8] Raben A, Macdonald I and Astrup A. (1997). Replacement of dietary fat by sucrose or starch: effects on $14 \mathrm{~d}$ ad libitum energy intake, energy expenditure and body weight in formerly obese and never-obese subjects. International Journal of Obesity Related Metabolic Disorders, 21, 846-859.

[9] Lucas-Aguirre J, Quintero-Castaño V and Cárdenas-Valencia A. (2013). Caracterización de harina y almidón obtenidos a partir de plátano guineo AAAea (Musa sapientum L.). Acta Agron, 62(2), 83-96.

[10] Abdullah A, Chalimah S, Primadona I and Hanantyo M. (2018). Physical and chemical properties of corn, cassava, and potato starchs. Earth and Environmental Science, 160, 012003.

[11] Cornejo-Ramírez Y, Martínez-Cruz 0, Del Toro-Sánchez C, Wong-Corral F, Borboa-Flores J and Cinco-Moroyoqui F. (2018). The structural characteristics of starches and their functional properties. CyTA - Journal of Food, 16(1), 1003-1017.

[12] Velásquez-Herrera J Lucas-Aguirre J and Quintero-Castaño V. (2017). Physical-chemical characteristics determination of potato (Solanum phureja Juz. \& Bukasov) starch. Acta Agronomica, 66(3), 323.

[13] Singh N, Singh J, Kaur L, Singh S and Singh G. (2003) Morphological, thermal and rheological properties of starches from different botanical sources. Food Chemistry, 81, 219-231.

[14] Shevkani K, Singh N, Bajaj R and Kaur A. (2017). Wheat starch production, structure, functionality and applications - a review. International Journal of Food Science \& Technology, 52, 38-58.

[15] Lohiniemi S, Maki M, Kaukinen K, Laippala P and Collin P. (2000). Gastrointestinal symptoms rating scale in coeliac disease patients on wheat starch-based gluten-free diets. Scandinavian Journal of Gastroenterology, 35, 947-949.

[16] Langton M and Hermansson A. (1989). Microstructural changes in wheat starch dispersions during heating and cooling. Food Microstructure, 8, 29-39.

[17] Li J, Vasanthan T, Hoover R and Rossnagel B. (2004). Starch from hull-less barley: IV Morphological and structural changes in waxy, normal and high-amylose starch granules during heating. Food Research International, 37, 417428.

[18] Buleon A, Colonna P, Planchot V and Ball S. (1998). Starch granules: structure and biosynthesis. International Journal of Biological Macro-molecules, 23, 85-112.

[19] Tester R and Morrison W. (1990). Swelling and gelatinization of cereal starches. Effects of amylopectin, amylose, and lipids. Cereal Chemistry, 67(6), 551-557.

[20] Bertoft E. (2017). Understanding starch structure: Recent progress. Agronomy, 7(3), 56.

[21] Takahashi S, Maningat C and Seib P. (1989). Acetylated and hydroxypropylated wheat starch: paste and gel properties compared with modified maize and tapioca starches. Cereal Chemistry, 66(6), 499-506.

[22] Kaur A, Singh N, Ezekiel R and Guraya H. (2007). Physicochemical, thermal and pasting properties of starches separated from different potato cultivars grown at different locations. Food Chemistry, 101(2), 643-651.

[23] Acosta-Osorio A, Herrera-Ruiz G, Pineda-Gómez P, Cornejo-Villegas M, Martínez-Bustos F, Gaytán M and Rodriguez García M. (2011). Analysis of the apparent viscosity of starch in aqueous suspension within agitation and temperature by using rapid visco analyzer system. Mechanical Engineering Research, 1(1), 110-124.

[24] Sulaiman R. (2011). Estimation of kinetic parameters in a corn starch viscosity model at different amylose contents. PhD Thesis. Michigan State University, 39-44. 
[25] Alcázar-Alay S and Meireles M. (2015). Physicochemical properties, modifications and applications of starches from different botanical sources. Food Science and Technology (Campinas), 35, 215-236.

[26] Reddy C, Pramila S and Haripriya S. (2015). Pasting, textural and thermal properties of resistant starch prepared from potato (Solanum tuberosum) starch using pullulanase enzyme. Journal of Food Science and Technology, 52(3), 1594-601.

[27] Ratnayake W and Jackson D. (2006). Gelatinization and solubility of corn starch during heating in excess water: New insights. Journal of Agricultural and Food Chemistry, 54(10), 3712-3716.

[28] Wang S, Chao C, Xiang F, Zhang X, Wang S and Copeland L. (2018). New insights into gelatinization mechanisms of cereal endosperm starches. Scientific Reports, 8(1), 3011.

[29] Noisuwan A, Hemar Y, Bronlund J, Wilkinson B and Williams M. (2007). Viscosity, swelling and starch leaching during the early stages of pasting of normal and waxy rice starch suspensions containing different milk protein ingredients. Starch/Staerke, 59, 379-387.

[30] Chen P, Liu X, Zhang X, Sangwan P and Yu L. (2015). Phase transition of waxy and normal wheat starch granules during gelatinization. International Journal of Polymer Science, 7.

\section{How to cite this article}

Popova AT. (2019). Heat-induced changes of corn, potato, and wheat starches. World Journal of Advanced Research and Reviews, 4(1), 37-43. 